\title{
III Brazilian Meeting on the Selenium and Tellurium Chemistry
}

In Brazil, chemistry started with the University of São Paulo (USP) creation in 1934. The previous attempts of making chemistry in the country were sporadic and ephemeral. The first research theme in this important science area in our country was the chemistry of selenium and tellurium organic compounds. The first review article in this special issue: Selenium and Tellurium Chemistry: Historical Background details this topic, so we will not expand on it.

This chemistry area only started being focused by the scientific community in other parts of the world in the second half of last century when biochemists demonstrated that the selenium element is essential for the health of both animals and human beings. ${ }^{1}$

A selenium-low diet (less than $55 \mu \mathrm{g} /$ day) leads to serious health problems such as cardiomyopathy and cartilage atrophy and degeneration. Such diseases come to affect about $90 \%$ of the population of areas in which the soil is selenium-poor, mainly in certain impoverished and isolated regions in China.

Curiously enough, a Brazil-nut a day would solve the problem because it accumulates huge quantities of selenium $(87 \mu \mathrm{g} / \mathrm{Se}$ per $5 \mathrm{~g}$ nut). This plant capacity of accumulating selenium can lead to a problem contrary to the one mentioned above.

In certain regions, because of the selenium excess, animals are affected by selenosis, characterized by the loss of hair, horns and hooves and other consequences. Even if the problem does not reach such proportions, the meat of the animals raised in places with a selenium-surplus soil, as in certain regions of Rio Grande do Sul State, can have a content of selenium superior to the allowed one, making the meat unfit for human consumption, mainly when destined for exportation to countries with a more rigorous control. This dual characteristic of the selenium element (up to a certain amount, beneficial; over it, harmful) is dealt with in this special issue in the article Diphenyl Diselenide: $a$ Janus-Faced Molecule.
Where does the selenium biological activity come from? The theme has nowadays been the object of intense studies in the medicine and biochemistry areas ${ }^{2-3}$ and it is already known that a considerable number of important enzymes contain selenocysteine in its active center, which came to be considered the $21^{\text {st }}$ natural amino acid from the 70's on. ${ }^{4}$ This is something rarely pointed out in the literature. Among the enzymes that contain selenocysteine in their active center, we emphasize the glutathione peroxidase, which is involved in the important process of detoxification of the mammals' organism, that is, the reduction of free radical precursors. ${ }^{3}$

Besides that, it was discovered that structurally-simple compounds of non-natural origin containing selenium or tellurium mimic that enzyme action, something that is being intensely researched nowadays. ${ }^{5}$ The article Catalytic Application of Selenium and Tellurium Compounds as Glutathione Peroxidase Enzyme Mimetics published in this special issue deals with this topic.

Still concerning the "benign" biological activity of the organic compounds containing selenium and tellurium, we point out its protease-inhibiting activity, generally present in the organisms, but that, in certain circumstances, such as viral infections, cancer, Alzheimer, etc turns to be produced in an unregulated, uncontrolled and undesirable way. This theme, a new and active work area, recently developed in Brazil, is treated in this special issue article Chemoenzymatic Synthesis of Organoselenium (IV) Compounds and their Evaluation as Cysteine Protease Inhibitors. ${ }^{7}$

Concerning synthetic applications of the selenium compounds, there is no need to emphasize their importance any more. Despite the many negative comments about their toxicity, nowadays some of these reagents are described even in undergraduation organic chemistry textbooks. Concerning the tellurium reagents, progress has been slower. However, at least one reaction involving this element has been established and it is more advantageous 
when compared with other methods that lead to similar results. That is the tellurium/metal exchange reaction, commented in this special issue in the article Reactive Organometallics from Organotellurides: Application in Organic Synthesis.

Several other articles dealing with the preparation and the applications of the selenium and tellurium organic and inorganic compounds can be found on the following pages. The utility of these elements' reagents is well demonstrated by the number of syntheses that make use of them. ${ }^{8}$

During the last 30 years, the group of Brazilian researchers dedicated to the study of the selenium and tellurium chemistry has acquired great visibility in Brazil and abroad, to an extent that some fellows think there are too many people focusing the area in Brazil. This is a fallacy, for the number of groups dedicated to this chemistry field in Brazil is small if compared to the groups dedicated to other traditional fields of chemistry. So, where does this visibility come from? The answer lies in the work philosophy of this group of researchers, which has always attempted to publish their research results in the best international journals. In order to do so, naturally, a great effort is made to keep the high level of their work. The best journals are the best because they publish what is top in a determined field.

In this sense, it is worth noting that the two most outstanding Brazilian chemists (number of articles multiplied by the journal impact factor) belong to this group. We believe that this is the greatest contribution that this group has given to the Brazilian chemistry: the consolidation of a research area by means of the dedication of several labs in an independent and continuous way for a long span of time, keeping itself at the knowledge frontier in that area at an international level. The existence of such "schools" should not be criticized; very much on the contrary, it would be very salutary that the several other Brazilian chemistry "schools" had the same national and international visibility.
In 2006, the chemists from Santa Maria Federal University engaged in the selenium and tellurium chemistry decided to hold biennial meetings for the sake of idea exchanging and possible redirection of their research subjects. The first of these meetings, held in Bento Gonçalves in 2006, was coordinated by Professor Ernesto S. Lang; the second one, coordinated by Professor Helio Stefani, happened in Campos do Jordão, in 2008 and the third one, organized by Antonio Braga will take place in Florianópolis, in December 2010 (http://www.qmc.ufsc.br/esete3).

We hope these meetings last long, thus contributing to maintain the Brazilian researchers engaged in this chemistry field at the frontier of knowledge at international level.

\section{Antonio L. Braga (UFSC) João V. Comasseto (USP)}

\section{References}

1. Schwarz, K.; Foltz, C. M.; J. Am. Chem. Soc. 1957, 79, 3292; Stapleton S. R.; Cell. Mol. Life Sci. 2000, 57, 1823.

2. Chasteen, T. G.; Bentley, R.; Chem. Rev. 2003, 103, 1; Mugesh, G.; du Mont, W. W.; Sies, H.; Chem. Rev. 2001, 101, 2125; Nogueira, C. W.; Zeni, G. R.; Rocha, J. B. T.; Chem. Rev. 2004, 104, 62550 .

3. Arthur, J. R.; Cell. Mol. Life Sci. 2000, 57, 1825.

4. Flohe, L.; Günzler, W. A.; Schock, H. H.; FEBS Lett. 1973, 32, 132; Stadtman, T. C.; J. Biol. Chem.; 1991, 266, 16257.

5. Mukherjee, A. J.; Zade, S. S.; Singh, H. B.; Sunoj, R. B.; Chem. Rev. 2010, 110, 4357; Bhabak, K. P.; Mugesh, G.; Acc. Chem. Res. 2010, in press, DOI: 10.1021/ar100059g.

6. Powers, J. C.; Asgian, J. L.; Ekici, O. D.; James, K. E.; Chem. Rev. 2002, 102, 4639.

7. Cunha, R. L. O. R.; Urano, M. E.; Chagas, J. R.; Almeida, P. C.; Bincoletto, C.; Tersariol, I. L. S.; Comasseto, J. V.; Bioorg. Med. Chem. Lett. 2005, 15, 755; Cunha, R. L. O. R.; Gouvea, I. E.; Juliano, L.; An. Acad. Bras. Cienc. 2009, 81, 393.

8. Freundendahl, D. M.; Santoro, S.; Shahazad, S. A.; Santi, C.; Wirth, T.; Angew. Chem. Int. Ed. 2009, 48, 8409; Wendler, E. P.; Dos Santos, A. A.; Synlett 2009, 1034; Comasseto, J. V.; Barrientos-Astigarraga, R. E.; Aldrichimica Acta 2000, 33, 66. 